\title{
George Sand, La Marquise, Lavinia, Metella, Mattea
}

\section{Annarosa Poli}

\section{(2) OpenEdition}

\section{Journals}

\section{Edizione digitale}

URL: http://journals.openedition.org/studifrancesi/36458

DOI: 10.4000/studifrancesi.36458

ISSN: 2427-5856

\section{Editore}

Rosenberg \& Sellier

\section{Edizione cartacea}

Data di pubblicazione: 1 juillet 2005

Paginazione: 187

ISSN: 0039-2944

\section{Notizia bibliografica digitale}

Annarosa Poli, «George Sand, La Marquise, Lavinia, Metella, Mattea», Studi Francesi [Online], 145 (XLIX I

I) | 2005, online dal 30 novembre 2015, consultato il 18 avril 2021. URL: http://

journals.openedition.org/studifrancesi/36458 ; DOI: https://doi.org/10.4000/studifrancesi.36458

\section{Questo documento è stato generato automaticamente il 18 avril 2021.}

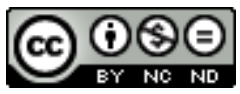

Studi Francesi è distribuita con Licenza Creative Commons Attribuzione - Non commerciale - Non opere derivate 4.0 Internazionale. 


\title{
George Sand, La Marquise, Lavinia, Metella, Mattea
}

\author{
Annarosa Poli
}

\section{NOTIZIA}

GEORGE SAND, La Marquise, Lavinia, Metella, Mattea, préface de Martine REID, Babel, Actes sud, 2002, pp. 304.

1 Le quattro novelle di George Sand scritte e pubblicate dal 1832 al 1835 erano già state riunite in questo ordine nel X volume delle Oeuvres complètes nel 1837. M. Reid si serve di questa edizione, preferendola a quella del 1861 che conteneva anche i testi di Pauline e di Melchior. La scelta è opportuna perché le quattro novelle formano un insieme coerente sia per la loro tematica che per il tono che le caratterizza.

2 Mattea si discosta per il quadro veneziano e per la giovane età della protagonista che lotta per liberarsi dalle imposizioni di una "madre padrona". Le figure femminili delle altre novelle, più mature di età, sono in preda a delusioni amorose o amareggiate dalla mediocrità dei loro compagni o dalla loro frivolezza di temperamento $\mathrm{e}$ incomprensione per le esigenze della donna. Lavinia rivendica la sua libertà con una delle più fiere affermazioni d'autonomia femminile uscita dalla penna di George Sand: "Et puis, je hais les engagements éternels. [...]. Je n'aime plus que les voyages, la rêverie, la solitude, le bruit du monde, pour le traverser et en rire...".

La «Marquise» ha ottant'anni e stupisce per la franchezza della sua confessione e per la sua diversità dalle nobildonne contemporanee del 1700. Delusa dal marito e dall'amante che gli usi di quella società imponevano, si innamora di un attore, Lélio. Amore platonico che è fatto soprattutto di ammirazione per la fervida interpretazione delle parti dei grandi eroi del passato nel teatro classico. La sua più grande delusione sarà quando incontrerà Lélio fuori dalla scena, un uomo volgare che non ha nulla di «eroico». Queste novelle posteriori a Indiana e Jacques sono il riflesso delle tematiche che caratterizzavano questi due romanzi ma anche di un rinnovamento nell'arte 
narrativa della scrittrice. Qui ricorre a un genere breve e riesce a sfruttare le sue migliori risorse: la concentrazione e la concisione degli argomenti e insieme una conclusione non sempre definitiva, di grande modernità. 